\section{AL-AZHAR Dental Journal}

F o r

\title{
Effect of Two Types of Surface Treatment of Dental Implants Retaining Mandibular Complete Overdenture on Bone Density Changes
}

\author{
Maie F. Khalil ${ }^{1 *}$, Mohamed E. Sanad ${ }^{2}$, Ghada A. Ahmed ${ }^{3}$, Asmaa N. Elboraey ${ }^{4}$
}

Codex : 04/2001

azhardentj@azhar.edu.eg

http://adjg.journals.ekb.eg

DOI: $10.21608 /$ adjg.2019.7524.1081

\begin{abstract}
Purpose: was to evaluate the influence of surface treatment of implant retained mandibular overdenture on peri-implant bone density. Resorbable Blast Media (RBM) implant surface treatment and acid etched implant surface treatment were used. Materials and Methods: Ten completely edentulous male patients were rehabilitated by mandibular over denture retained by two dental implants in the interforaminal region, the one on the right side was acid etched and the left side was with resorbable blast media (RBM). Peri- implant bone density was assessed with cone beam computed tomography at the time of implant loading, six months and twelve months after denture insertion. Results: There was no significant difference between Acid etched and RBM dental implants on the peri-implant bone density during the follow up period. Conclusion: Within the limitations of the number of studied patients it could be stated that Acid etched and RBM dental implants fulfill the criteria of dental implant success and are recommended to be used.
\end{abstract}

\section{INTRODUCTION}

Edentulous patients encounter many problems related to conventional complete dentures, this contributed to inadequate retention and instability, pain, decreased oral function, nutrition insufficiency and psychological problems ${ }^{()}$.

- Paper extracted from Doctor Thesis titled "Effect of Two Types of Surface Treatment of Dental Implants Retaining Mandibular Complete Overdenture on Bone Density and Marginal Bone Height Changes"

1. Assistant Researcher at National Research Center

2. Professor of Removable Prosthodontics, Faculty of Dental Medicine for Girls, Al-Azhar University.

3. Professor of Oral Surgery, Faculty of Dental Medicine for Girls, Al-Azhar University

4. Researcher of Fixed and Removable Prosthodontics Department, Oral and Dental Research Division, National Research Centre

* Corresponding author Email: maiyoy.jannah1@gmail.com 
Numerous studies revealed that various strategies have been developed to control these problems such as the use of dental implants, to support overdentures which provides more advantages than conventional mucosa supported complete and partial denture, some of which are decreased bone resorption, reducing or eliminating movements of the prosthesis, better esthetics, enhanced tooth positions and improving occlusal load distribution ${ }^{\circ}$.

The completely edentulous mandible can be restored by several treatment plans such as mucosa supported complete dentures, fixed implant supported prosthesis, implant retained overdentures or implant retained and supported overdentures ${ }^{0}$.

Edentulous mandible restored with a complete denture does not become the most convenient choice for treatment. It has been suggested that two implant supported and/or retained overdenture is the first line of treatment for nedentulous mandible ${ }^{0}$.

Implant surface characteristics is one of the implant design factor that affect the progress of osseointegration. Different approaches have been introduced to produce a rough surface to enhance the osseointegration of titanium dental implants. Several surface modifications have been developed as blasted, acid-etched, oxidized, plasmasprayed, surfaces with hydroxyapatite coating and combinations of these procedures.

Surface treatment using resorbable blast media (RBM) employs calcium phosphate as a biocompatible substance, to increase the surface area of implants and offer more implant -to- bone contact. RBM-treated materials have osteoconductive properties thus enhancing the maturation of bone cells. RBM surface treatment provides implants with very clean surfaces that increase gathering of osteoblast cells. Besides, surfaces treated with RBM become hydrophilic that's allowed rapid attraction of blood and blood cells. This is beneficial and helpful for the success of implant restorations because the cells are essential to stimulate bone formation on the implant ${ }^{(.)}$.
Titanium surfaces treated with acid-etching possess micro roughness ranging from 0.5 to $2 \mu \mathrm{m}$ in diameter. It has been shown that surfaces treated with acid etching with roughness of $0.6 \mu \mathrm{m}$ to $0.9 \mu \mathrm{m}$ have greater removal torque values and increased the contact between bone and implant more than machine grit blast implants ${ }^{0}$.

Cone beam computed tomography (CBCT) becomes the first imaging techniques in implant therapy. The quality, accuracy, and precision of the images increase the precision of implant placement, improving the prognosis of implant supported prostheses.

CBCT provides exact and correct measurements more than Multi slice computed tomography (MSCT). CBCT characterized by decreased costs and reduces the doses of radiation, so it is commonly used for implant placement.

Although, Long term studies have been published evaluating the effect of different implant surface structure on the peri-implant bone changes, however researches are still needed to study the effect of Resorbable Blast Media (RBM) surface treatment of dental implants on peri-implant bone density.

Hence, the purpose of this study was to evaluate the effect of two different types of surface treatment on the bone density around dental implants retaining mandibular complete overdentures.

\section{MATERIAL AND METHODS}

Ten completely edentulous patients were selected from the outpatient clinic of Prosthodontic Department, Faculty of Dental Medicine Al-Azhar University and National Research Centre clinic to participate in this study, their age ranged between 50-60 years, having no systemic disease that may affects healing, complicates surgical procedures or contributes to bone resorption and having no history of abnormal habits. 
Patient preparation: Detailed information about the treatment was given to all the patients; the surgical and prosthetic steps, the risks and the benefits and the implant treatment alternatives were explained thoroughly and patients signed a written consent with the Research Ethics Committee (REC) approval. The selection criteria were fulfilled through routine diagnostic procedures including history taking (medical and dental), clinical examination (extraoral and intra-oral), laboratory investigation and radiographic examination. Complete upper and lower dentures were constructed and delivered following the conventional technique.

Radiographic stent: The patient existing mandibular complete denture was used as a radiographic stent after application of radio-opaque reference marks (gutta percha) at different planes on the facial and lingual surfaces of the mandibular denture to assess the anatomy of bone at the proposed implant sites in the patients.

Radiographic imaging: A cone beam computed tomography (CBCT) image was produced for the lower jaws and the resultant image was obtained as DICOM (digital imaging and communications in medicine) data on a compact disc.

Virtual planning and surgical guide fabrication: The obtained DICOM files were imported to specialised software (Blueskybio) for virtual planning. The proposed implant sites were the canine regions (bilaterally). The proposed sites were identified by the gutta percha cones attached to the radiographic stent and were evaluated for sufficient bone height and width. The proposed implant diameter was $3.7 \mathrm{~mm}$ and length to be $12 \mathrm{~mm}$.

Once the positions of implants were accepted in the virtual guide, the $3 \mathrm{D}$ virtual stent was processed by special software (Bluesky Bio) using 3D printer (fig.1).

Surgical procedures for implant installation: Patients were rehabilitated by mandibular over denture retained by two dental implants $(3.7 \mathrm{~mm}$ in

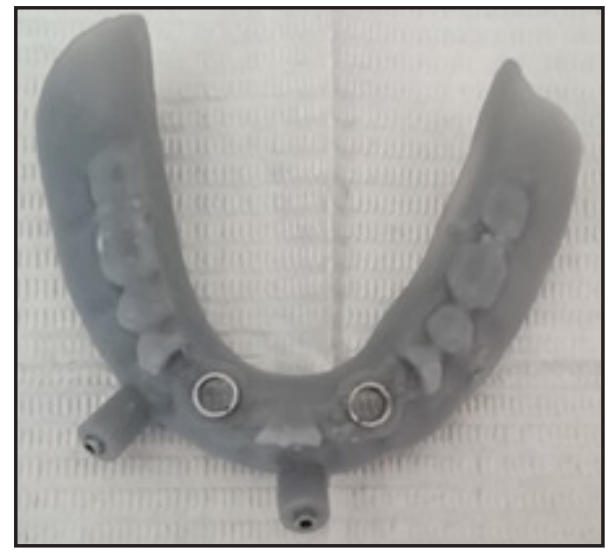

Figure(1) Surgical stent

diameter and $12 \mathrm{~mm}$ in length) in the interforaminal region with different surface treatment, the one on the right side was acid etched and the left side was with resorbable blast media (RBM).

First surgical stage: On the day of the surgery, inferior alveolar nerve block anaesthesia was given to both sides of the arch beside infiltration anesthesia in the symphyseal area of the mandible.

The surgical stent was fixed using fixation screws and the osteotomy was performed using three sequential drills $(2.2 \mathrm{~mm}, 2.8 \mathrm{~mm}, 3.7 \mathrm{~mm})$. "Drill guide" was used to guide the drill during osteotomy preparation.

After the osteotomy sites were finally prepared each implant was carried with its fixture mount and inserted manually in the osteotomy site, then the fixture mount was removed and further tightening was continued using torque ratchet until the top of the implant flushed with the bone surface using depth controlling implant driver.

After installation of all implants the covering screws were inserted and screwed over the implant fixtures

Second surgical stage: Patients were recalled after one month. The surgical stent was used as a guide for implant position. Local anaesthesia was infiltrated at the implant site, and tissue punch 
presented in the surgical kit was used to expose the implant screws. The cover screws were unthreaded using screw driver and cholorohexidene mouthwash was used to irrigate the implant from inside. For all patients, ball attachments with its metal housing were placed over the implant, holes were prepared in the fitting surface of the denture using a round bur, so that the denture fits passively onto the newly placed implants. The denture was checked to fit over the implants with their housings without interfering with the original fit of the denture. The attachment system were picked up into the mucosal surfaces of the overdentures using a pink, fast cold-cure acrylic resin (Fig.2). The patients were instructed to occlude on the dentures till the material set. Any excess material was removed and the denture was finished.

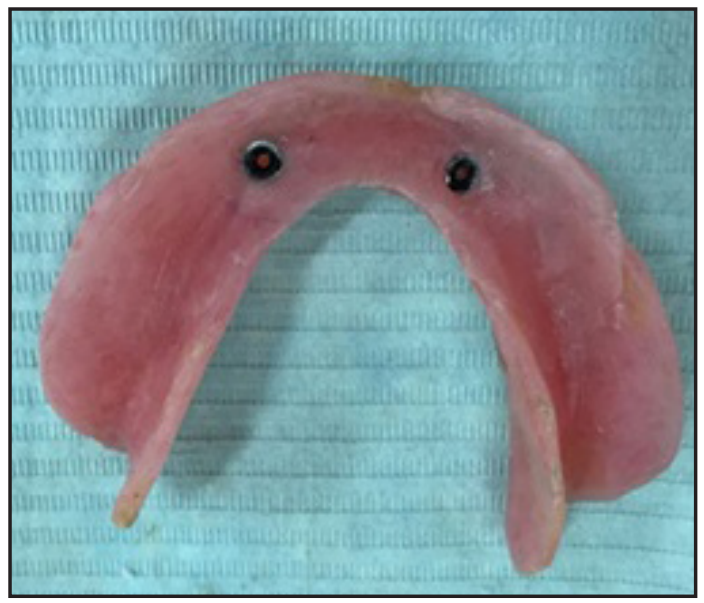

Figure (2) The denture after pick up of the metal housings

Patient's radiographic evaluation: Patients were frequently recalled for inspection, post insertion adjustments and for radiographic examination at the time of implant loading as well as six and twelve months after loading to evaluate the peri-implant bone density changes.

The bone density measurements were given in Hounsfield units (HU) supplied by the cone beam computed tomography (CBCT) (kVp.120, mA . 37.07 , Field of view $7 \times 14.5 \times 14.5 \mathrm{~cm}$ ).
Image analysis for bone density measurement: Bone density was measured in a rectangular area on each axial surface of the implant (Buccal, Lingual, Mesial and Distal) (fig.3).

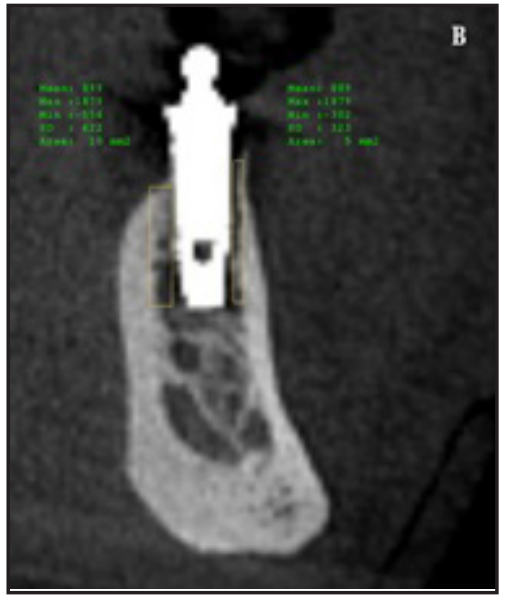

Figure (3) Bone density of the buccal and lingual surfaces of the left implant at loading

\section{Statistical analysis}

All measurements were recorded and tabulated. Statistical analysis was performed with Microsoft Excel ® 2010 and Statistical Package for Social Science (SPSS) ${ }^{\circledR}$ Ver. 20. ANOVA test was used to study the changes by time within each group as well as to compare between the two groups.

\section{RESULTS}

\section{Changes after treatment within each group}

In both groups; there was a statistically significant increase in mean bone density after 6 months as well as from 6 months to 12 months (table 1).

\section{Comparison between the two groups}

At base line, after 6 as well as 12 months; there was no statistically significant difference between bone density measurements in the two groups (table 2). 
Table (1): The mean, standard deviation (SD) values and results of two-way repeated measures ANOVA test for comparison between bone densities through the follow up periods within each group

\begin{tabular}{|c|c|c|c|c|c|c|c|}
\hline \multirow{2}{*}{ Surface treatment } & \multicolumn{2}{|c|}{ Base line } & \multicolumn{2}{|c|}{6 months } & \multicolumn{2}{|c|}{12 months } & \multirow[b]{2}{*}{ P-value } \\
\hline & $\mathrm{Md}^{*}$ & $\mathrm{SDd}^{* *}$ & Md & SDd & $\mathrm{Md}$ & SDd & \\
\hline Acid etch & $1057.30 \mathrm{C}$ & 77.53 & 1231.05 & 63.79 & 1331.30 & 105.42 & $<0.001 \mathrm{~s} * * *$ \\
\hline RBM & $1108.75 \mathrm{C}$ & 101.53 & 1219.40 & 90.16 & 1312.40 & 61.98 & $<0.001 \mathrm{~s} * * *$ \\
\hline
\end{tabular}

$* \mathrm{Md}=$ Mean difference $* * \mathrm{SDd}=$ standard deviation deference $* * * \mathrm{~s}=$ significant.at $\mathrm{P} \leq 0.05$

Table (2): The mean, standard deviation (SD) values and results of two-way repeated measures ANOVA test for comparison between bone density measurements in the two groups

\begin{tabular}{|c|cc|cc|c|}
\hline \multirow{2}{*}{ Time } & \multicolumn{2}{|c|}{ Acid etch } & \multicolumn{2}{|c|}{ RBM } & \multirow{2}{*}{ P-value } \\
\cline { 2 - 5 } & Md* & SDd** & Md & SDd & $0.070 \mathrm{~ns}^{* * *}$ \\
\hline Base line & $1057.30 \mathrm{C}$ & 77.53 & 1108.75 & 101.53 & $0.630 \mathrm{~ns}^{* * *}$ \\
\hline 6 months & 1231.05 & 63.79 & 1219.40 & 90.16 & $0.398 \mathrm{~ns}^{* * *}$ \\
\hline
\end{tabular}

$* M d=$ Mean difference. $\quad * * S D d=$ Standard deviation difference. $\quad * * * n s=$ Non-significant.

\section{DISCUSSION}

Various research studies have revealed that implant overdentures offer better advantages than complete dentures, including patient satisfaction, chewing efficiency and oral-health-related quality of life. A mandibular two implants supported overdenture is a successful and efficient treatment modality with prolonged standpoint ${ }^{(\cdot)}$. It is recommended to be the first treatment option for the edentulous mandible ${ }^{(5,)}$.

The conservation of peri-implant bone density is important factor for long-term implant success. Ideally, the goal of any prosthetic dental treatment is to provide a durable and satisfactory prosthesis that maintains the health of the supporting structures. Thus, implant surface treatment is one of the major factors that affect the osseointegration of the dental implants supporting and retaining the overdentures o. Consequently, the present study was established to compare the effect of two different types of implant surface treatment on peri-implant bone density.

Ten completely edentulous patients were selected. Each of them received two implants with different surface treatments, the one on the right side was acid etched and the left side was with resorbable blast media (RBM). Split mouth technique was used to decrease human variables and exclude any factors or habits that may adversely affect the results of this study. The goal of split-mouth trials is to eliminate subject variability and to standardize the patient factor ${ }^{0}$.

The interforminal region was advocated because bone density for implant support is usually optimum at this region. It is characterized by thick dense cortical bone plates and dense trabecular bone or opposing cortex at the inferior border which is in contrast to that posteriorly ${ }^{(4)}$. 
Standard clinical and laboratory techniques were followed for the construction of the dentures for all patients. Also, the same materials were used as feasible as an attempt to remove any factor that may affect the results of this study.

Cone beam computed topography was used to make the computerized surgical guide. CBCT was the imaging technique in this study. It is characterized by faster collection of the data set of the whole field of view (FOV). It involves a shorter examination time, reduced radiation dose, better image sharpness, reduced image distortion, and increased $x$-ray efficiency ${ }^{\circ}$.

Surgical drilling guides were fabricated from the virtual treatment plan. The aim of the surgical guides is to allow the placement of the implants accurately in the exact positions as planned virtually, resulting in more precise and liable implant placement and enhances the prognosis ${ }^{\text {). }}$.

The bone density was measured in selected areas adjacent to acid etched and RBM implants and it was increased across the follow up periods and subsequently increased the implant stability. This was in accordance with, surface treatments improve biological surface properties, which increase mineralization and favor the mechanism of osseointegration ${ }^{\circ}$.

The bone density was increased around the acid etched implants more than that for the RBM implants. This difference was not statistically significant, but indicated the acid-etched surfaces have a slightly better performance than the RBM surface.

\section{CONCLUSION}

Within the limitations of the number of studied patients and follow up period it could be stated that Acid etched and RBM dental implants fulfill the criteria of dental implant success and are recommended to be used.

\section{REFERENCES}

1. Quirynen M, Alsaadi G, Pauwels M, Haffajee A, Van Steenberghe D, N Ignace. Microbiological and clinical outcomes and patient satisfaction for two treatment options in the edentulous lower jaw after 10 years of function. Clin Oral Implants Res. 2005;16:277-87.

2. Zitzmann NU, Marinello CP. Treatment outcomes of fixed or removable implant-supported prostheses in the edentulous maxilla. Part I: patients' assessments. J Prosthet Dent. 2000; 83:424-33.

3. Zitzman NU, Marinello CP. Patient satisfaction with removable implant supported prosthesis in edentulous mandible. Schweiz Monatsschr Zahnmed. 2006;116: 237-44.

4. W Chee, S Jivraj. Treatment planning of the edentulous mandible. Bri Dent J. 2006;201:337-7.

5. Feine JS, Carlsson GS, Awad MA, Chehade A, Duncan WJ, Gizani S, et al. The McGill consensus statement on overdentures. Int J Prosthodont. 2002; 15:413-4.

6. Rosa MB, Albrektsson T, Francischone CE, Schwartz Filho HO, Wennerberg A. The influence of surface treatment on the implant roughness pattern. J Appl Oral Sci. 2012; 20:550-5

7. Piattelli M, Scarano A, Paolantonio M, Iezzi G, Petrone G, Piattelli A. Bone response to machined and resorbable blast material titanium implants: an experimental study in rabbits. J Oral Implantol. 2002;28:2-8.

8. Ong JL, Carnes DL, Bessho K. Evaluation of titanium plasma sprayed and plasma-sprayed hydroxyapatite implants in vivo. Biomat. 2004; 25:4601-6.

9. Ma S, Tawse-Smith A, Thomson WM, Payne AG. Marginal bone loss with mandibular two-implant overdentures using different loading protocols and attachment systems: 10year outcomes. Int J Prosthodont. 2010; 23:321-32.

10. Vercruyssen M, Marcelis K, Coucke W, Naert I, Quirynen M. Long-term, retrospective evaluation (implant and patientcentred outcome) of the two-implants-supported overdenture in the mandible. Part 1: survival rate. Clin Oral Implants Res. 2010; 21:357-65.

11. Thomason JM, Kelly SA, Bendkowski A, Ellis JS. Two implant retained overdentures-a review of the literature supporting the McGill and York consensus statements. J Dent. 2012; 40:22-34. 
12. Darwish M, Nassani MZ, Baroudi K. Effect of neutral zone technique on marginal bone loss around implantsupported overdentures. J Int Soc Prev Community Dent. 2015; 2: 57-62.

13. Al-Almaie S, Kavarodi A, Alorf A, and Alzahrani S. A SplitMouth Design: Short Comparison for Lateral and Crestal Sinus Lift Techniques with Dental Implants Placements Communication. Open Dent J. 2017; 11: 603-8.
14. Gupta S, patil N, Solanki J, SinGh R, laller S. Oral Implant Imaging: A Review. Malays J Med Sci. 2015; 22: 7-17.

15. Mischkowski RA, Zinser MJ, Ritter L, Neugebauer J, Keeve E. Intraoperative navigation in the maxillofacial area based on 3D imaging obtained by a cone-beam device. Int J Oral Maxillofac Surg. 2007; 36: 687-94.

16. Wennerberg A, Albrektsson T, Zöller JE. On implant surfaces: a review of current knowledge and opinions. Int J Oral Maxillofac Implants. 2010; 25:63-74. 